\title{
ANALISIS TUTURAN IMPERATIF BAHASA JAWA GURU PADA SISWA KELAS II MI AL-FATTAH KOTA MALANG
}

\author{
Hullatun Waqori \\ MI Al- Fattah Kota Malang \\ email :waqori.spd@gmail.com
}

\begin{abstract}
Abstrak
Penelitian ini bertujuan untuk (1) mendeskripsikan wujud pragmatik imperatif pada guru MI Al-Fattah , (2) mendeskripsikan kesantunan imperatif, meliputi kesantunan linguistik dan kesantunan pragmatik. Jenis penelitian dalam penelitian ini adalah deskriptif kualitatif karena data yang diambil berupa tuturan-tuturan lisan bukan angka. Subjek penelitian ini adalah guru MI Al-Fattah . Objek penelitian ini adalah tuturan imperatif yang dituturkan oleh guru. Data diperoleh dengan metode simak bebas libat cakap (SLBC), teknik rekam, dan teknik catat. Data dianalisis dengan metode analisis konten (content analysis). Metode analisis konten merupakan metode untuk menganalisis data dengan cara mengaitkan tuturan dengan konteksnya. Kemudian hasil data yang telah dianalisis tersebut disajikan secara deskriptif. Hasil penelitian ini diperoleh (1) Wujud pragmatik imperatif yang digunakan guru MI Al-Fattah pada proses belajar mengajar diperoleh 10 wujud. (2) wujud kesantunan imperatif, meliputi (a) wujud kesantunan linguistik, kesantunan linguistik yang ditemukan dalam penelitian di MI Al-Fattah dalam proses belajar mengajar yaitu panjang pendek tuturan, urutan tutur, intonasi dan isyarat kinestik, ungkapan-ungkapan penanda kesantunan yang meliputi penanda kesantunan tulung, ayo, coba, mbok/mbokan, (b) kesantunan pragmatik imperatif, kesantunan pragmatik imperatif meliputi kesantunan pragmatik imperatif dalam tuturan deklaratif dan interogatif. Kesantunan pragmatik dalam tuturan deklaratif ditemukan deklaratif yang bermakna pragmatik imperatif suruhan, deklaratif yang bermakna pragmatik imperatif persilaan, dan deklaratif yang bermakna pragmatik imperatif larangan, sedangkan dalam bentuk interogatif ditemukan interogatif yang bermakna pragmatik imperatif perintah dan interogatif yang bermakna pragmatik imperatif larangan.
\end{abstract}

Kata kunci: Tuturan imperatif, Guru MI, Bahasa Jawa

\section{A. PENDAHULUAN}

Bahasa adalah sebagai satu sistem lambang bunyi yang bersifat "arbitrer". Bahasa pada prinsipnya merupakan alat untuk berkomunikasi dan alat untuk menunjukkan identitas masyarakat pemakai bahasa. Suatu kenyataan bahwa manusia mempergunakan bahasa sebagai sarana komunikasi vital dalam kehidupan. Bahasa memegang peranan penting dalam kehidupan kita hal ini harus kita sadari benar- benar, khususnya para guru bahasa sebagai sarana komunikasi vital dalam berkomunikasi dengan siswanya untuk berinteraksi. Kalimat imperatif adalah kalimat yang isinya meminta agar si pendengar atau yang mendengar kalimat itu memberi tanggapan berupa tindakan atau perbuatan yang diminta. Kalimat imperatif mengandung maksud memerintah atau meminta agar mitra tutur melakukan suatu sebagaimana diinginkan penutur.

\footnotetext{
${ }^{1}$ http://KBBI.online.com/2014/12/3/bahasa, diakses tanggal 03 Maret 2018

Vol. 1 No. 1 / April 2018

Al - Mudarris homepage: http://e-journal.staima-alhikam.ac.id/index.php/al-mudarris/
} 
Dalam pembelajaran di MI khususnya kelas II, guru memegang kontrol serta power atas siswanya. Hal ini dapat diidentifikasi dari dominasinya tuturan yang berasal dari guru dibandingkan tuturan-tuturan dari siswa saat pembelajaran sedang berlangsung. Dominannya pemanfaatan tuturan imperatif dalam proses pembelajaran di MI sangat dipengaruhi oleh faktor usia atau faktor umur siswa yang relatif masih sangat muda, yaitu berkisar 7-8 tahun. Pada usia tersebut anak sangat membutuhkan lebih banyak kontrol serta pengawasan dalam bentuk perintah dari gurunya. Selama proses belajar megajar berlangsung tidak setiap saat guru menggunakan tuturan imperatif secara langsung, adakalanya menggunakan wujud nonimperatif seperti bentuk deklaratif dan interogatif. Dari uraian mengenai latar belakang tersebut, peneliti tertarik untuk mendeskripsikan penelitian yang berjudul "Analisis tuturan imperatif Bahasa Jawa Guru Madrasah Ibtidaiyah Al-Fattah pada siswa kelas II MI Al-Fattah Kecamatan Lowokwaru Kota Malang". Penelitian ini bertujuan untuk mendeskripsikan wujud pemakaian tuturan pragmatik imperatif, mendeskripsikan faktor-faktor ungkapan penanda kesantunan tuturan imperatif yang digunakan oleh guru dalam proses belajar mengajar.

\section{B. METODE PENELITIAN}

Jenis penelitian yang digunakan dalam penelitian ini adalah deskriptif kualitatif. Penelitian ini dilakukan di MI Al-Fattah dilakukan selama 15 hari tanggal 1 Maret samap 16 Maret 2018 pada saat proses mengajar berlangsung. Subjek penelitian ini adalah guru MI Al-Fattah. Objek penelitian dalam penelitian ini adalah tuturan imperatif guru MI Al-Fattah. Data diperoleh dengan metode simak bebas libat cakap (SLBC), teknik rekam, dan teknik catat. Instrumen atau alat bantu yang digunakan dalam penelitian ini meliputi alat rekam berupa handphone, alat tulis (kertas) dan bolpoin. Penulis juga menggunakan buku-buku yang sesuai atau relevan untuk menganalisis percakapan yang telah diperoleh agar data yang dianalisis valid. ${ }^{2}$

Data dianalisis dengan metode analisis konten (content analysis). Metode analisis konten merupakan metode untuk menganalisis data dengan cara mengkaitkan tuturan dengan konteksnya. ${ }^{3}$ Adapun hasil analisis data disajikan secara informal, yaitu dengan kata-kata biasa. ${ }^{4}$

\section{HASIL PENELITIAN}

\section{Wujud Pragmatik Imperatif}

Dalam penelitian ini, sedikitnya ditemukan sepuluh macam wujud pragmatic imperatif yaitu imperatif perintah, suruhan, permintaan, desakan, bujukan, himbauan, ajakan, larangan, anjuran, "ngelulu".

a. Tuturan yang Mengandung Makna Pragmatik Imperatif Perintah

(1) Tutupke lawang!"

*Tutupake laway!+

'Tutupkan pintu!' (Rekaman 2)

${ }^{2}$ Arikunto, Prosedur Penelitian Suatu Pendekatan Praktik (Jakarta: Rineka Cipta, 2013), hlm. 203.

3 Mulyana, Kajian Wacana: Teori, Metode dan Aplikasi Prinsip-prinsip Wacana (Yogyakarta: Tiara Wacana, 2005), hlm. 82.

\footnotetext{
${ }^{4}$ Sudaryanto, Metode dan Aneka Teknik Analisis Bahasa Pengantar Penelitian Wahana Kebudayaan Secara Linguistik (Yogyakarta: Duta Wacana University Press 1993), hml. 145.
}

Vol. 1 No. 1 / April 2018

$\mathrm{Al}$ - Mudarris homepage: http://e-journal.staima-alhikam.ac.id/index.php/al-mudarris/ 
Pada tuturan di atas mengandung makna pragmatik imperatif perintah, tuturan itu memerintahkan kepada siswa supaya menutupkan pintu. Tuturan tersebut dapat dikatakan memiliki tingkat kesantunannya sangat rendah karena tidak dibubuhinya penanda kesantunan apapun.

b. Tuturan yang Mengandung Makna Pragmatik Imperatif Suruhan

(1) "Ahmad disimak coba, bene presa tekan ngendhi ayo!"

[Ahmad disima? coba, bene presa təkan ngəndi ayo!+ 'Ahmad disimak coba, biar tau sampai mana ayo!' (Rekaman 2) Konteks tuturan: Dituturkan guru pada saat guru membacakan cerita siswa tidak memperhatikan.

Pada tuturan di atas mengandung makna pragmatik imperatif suruhan dengan membubuhkan kata "coba" maka kadar tuntutan dalam impertaif suruhan cenderung lembut dan lunak. Hal ini akan berbeda apabila penanda kesantunan tersebut dihilangkan, menyebabkan tuturan itu memiliki kadar tuntutan yang langsung, keras dan kasar sehingga ditafsirkan sebagai tuturan yang mengandung maksud imperatif perintah.

c. Tuturan yang Mengandung Makna Pragmatik Imperatif Permintaan

(1) "Tulung digateake to!"

*Tuluy digatcake to!+ 'Tolong diperhatikan to!' (Rekaman 4)

Tuturan di atas yang dituturkan oleh guru kepada siswa merupakan tuturan yang mengandung makna pragmatik imperatif permintaan, guru meminta agar siswa memperhatikan. Tuturan tersebut memiliki tingkat kesantunan yang tinggi karena dibubuhi penanda kesantunan "tulung", sehingga kadar tuntutanya cenderung rendah.

d. Tuturan yang Mengandung Makna Pragmatik Imperatif Desakan

(1) "Milih ayo cepet, ayo soale digarap!"

[Milih ayo cəpet soale digarap!]

'Milih ayo cepat, ayo soalnya dikerjakan!' (Rekaman 4)

Sebagai tuturan yang mengandung makna pragmatik imperatif desakan, tuturan

di atas memiliki kadar tuntutan yang tinggi meskipun tuturan tersebut dibubuhi penanda kesantunan "ayo". Tingginya kadar tuturan yang terkandung dalam tuturan tersebut disebabkan perubahan intonasi yang meninggi saat menuturkan tuturan tersebut. Pada tuturan di atas guru mendesak supaya siswa segera mengerjakan soal.

e. Tuturan yang Mengandung Makna Pragmatik Imperatif Bujukan

(1) "Mriki maju mriki, ayo bukune diasta ayo majeng!" * Mriki maju mriki ayo bukune diasta ayo majəy!] 'Sini maju sini, ayo bukunya dibawa ayo kedepan!' (Rekaman 2)

Pada tuturan di atas yang dituturkan guru kepada siswa mengandung imperatif bujukan, guru membujuk siswa supaya mau maju kedepan, dengan penggunaan penanda kesantunan "ayo" dan dengan intonasi yang lembut tuturan itu memiliki tingkat kesantunan yang tinggi.

f. Tuturan yang Mengandung Makna Pragmatik Imperatif Himbauan

(1) Sapa sing arak nyatet, nyateta cepet cekat-ceket!

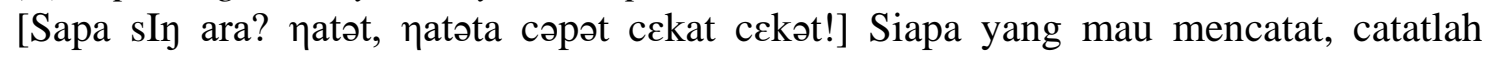
cepat! (Rekaman 3)

Pada tuturan yang dituturkan oleh guru kepada siswa mengandung imperatif himbauan karena digunakan bersamaan dengan partikel -lah tuturan tersebut memiliki tingkat kesantunan yang tinggi.

g. Tuturan yang Mengandung Makna Pragmatik Imperatif Ajakan

(1) "Nomer pitu ayo dipresani gambar!"

*Nomər pitu ayo dipresani gambar!]

Vol. 1 No. 1 / April 2018

$\mathrm{Al}$ - Mudarris homepage: http://e-journal.staima-alhikam.ac.id/index.php/al-mudarris/ 
'Nomor tujuh ayo dilihat gambar!' (Rekaman 4)

Pada tuturan di atas yang dituturkan oleh guru kepada siswa mengandung makna imperatif ajakan. Tuturan itu guru mengajak siswa untuk melihat gambar, tuturan itu muncul setelah guru mendapati ada siswa ribut sendiri saat guru membacakan soal.

h. Tuturan yang Mengandung Makna Pragmatik Imperatif Larangan

(1) "Wulan....Wulan ayo mboten pareng rame kiyambak!" *Wulan..Wulan ayo mbotən parəy rame kiyamba?!+ 'Wulan....Wulan ayo tidak boleh ramai sendiri!' (Rekaman 4)

Pada tuturan di atas memiliki makna imperatif larangan supaya siswa tidak ramai sendiri. Makna imperatif larangan tersebut semakin kentara dengan munculnya kata "mboten pareng" sebagai pemertegas imperative larangan.

i. Tuturan yang Mengandung Makna Pragmatik Imperatif Anjuran

(1) "Tumbas nang koperasi neng bu gurune nonok, anane nek ngaso mangken nek istirahat!

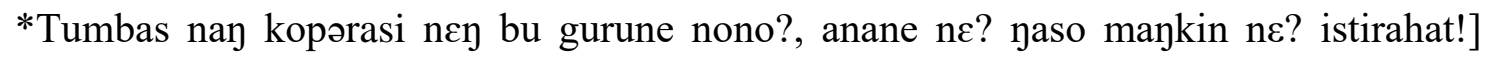
'Beli di koperasi tapi bu gurunya tidak ada, adanya kalau istirahat nanti kalau istirahat!' (Rekaman 2)

Pada tuturan di atas mengandung makna anjuran dalam bentuk non imperatif, tuturan (1) mengandung makna pragmatik imperatif anjuran supaya siswa membeli penghapus waktu istirahat. j. Tuturan yang Mengandung Makna Pragmatik Imperatif "Ngelulu"

(1) "Riyan le lenggah teng pundhi Riyan, empun mriko nek arak metu nek arak lenggah neng kana oleh!” *Riyan le ləygah tin pundi Riyan, əmpUn mrika ne? ara? mətu ləngah ney kana olkh!]

'Riyan duduknya di mana Riyan, sudah sana kalau mau keluar kalau mau duduk disana boleh!' (Rekaman 6)

Pada tuturan (1) mengandung makna "ngelulu", pada tuturan diatas guru menyuruh siswa untuk duduk di luar namun sebenarnya melarang siswa untuk duduk diluar, dengan dituturkannya tuturan itu supaya siswa duduk dengan bagus.

2. Faktor-Faktor Penanda Kesantunan

Wujud kesantunan linguistik pemakaian tuturan imperatif guru yang ditandai oleh beberapa unsur, yakni (a) panjang pendek tuturan, (b) urutan tuturan, (c) intonasi dan isyarat kinestik, (d) ungkapan-ungkapan penanda kesantunan sebagai penentu kesantunan linguistik. Adapun wujud kesantunna pragmatik yang ditemukan yaitu (a) tuturan yang mengandung tuturan deklaratif dan (b) interogatif tuturan itu dapat dilihat pada tuturan di bawah ini.

a. Kesantunan Linguistik

1) Panjang Pendek Tuturan

(a) "Disimak tulisane!"

[Disima? tulisane!]

'Disimak tulisannya!' (Rekaman 6)

(b) "Dipresani tulisane mangkin ngisi lho!"

*Dipresani tulisane mankin nisi lho!+

'Dilihat tulisnnya nanti mengerjakan lho!' (Rekaman 6)

(c) "Afriyan dipresani tulisane, aja karo bobok ora saged mesthi nangis

njuan to!" [Afriyan dipresani tulisane, aja karo bobo?! ora sagəd məsţi nayis njUan to!

'Afriyan dlihat tulisannya, jangan sambil bobok tidak bisa nan ti terus nangis!' (Rekaman 6)

Vol. 1 No. 1 / April 2018

$\mathrm{Al}$ - Mudarris homepage: http://e-journal.staima-alhikam.ac.id/index.php/al-mudarris/ 
Tuturan (1a) sebanyak dua kata, tuturan (1b) lima kata dan tuturan (1c) sebanyak enam kata dan merupakan tuturan yang terpanjang. Dari ketiga tuturan itu dapat dikatakan bahwa dari segi kesantunan tuturan (1a) secara linguistik berkadar kesantunan paling rendah, sedangkan tuturan (1c) berkadar kesantunan paling tinggi. Dengan demikian dapat dikatakan bahwa semakin panjang sebuah tuturan menjadi semakin santun tuturan itu.

2) Urutan Tuturan

(1) "Ayo digarap tese lek ndang! Cepet!"

[Ayo digarap tese le? ndan cəpət!]

'Ayo segera dikerjakan tesnya! Cepat!' (Rekaman 7)

Tuturan di atas memiliki tingkat kesantunan yang tinggi karena untuk menyatakan maksud imperatifnya tuturan itu diawali terlebih dahulu dengan informasi yang melatarbelakangi imperatif yang dinyatakan selanjutnya.

3) Intonasi dan Isyarat Kinestik

(1) "Hesti..Hesti, madhep mriki!"

[Hesti... Hesti madəp mriki!]

'Hesti..Hesti, menghadap kesini!' (Rekaman 6)

Munculnya isyarat paralingustik berupa gerakan tangan yang menyertai guru saat menuturkan tuturan tersebut memiliki fungsi pemertegas supaya siswa mau menghadap ke arah guru.

4) Ungkapan-Ungkapan Penanda Kesantunan

(1) "Tulung digateake ta!"

[Tulung digatcake to!]

'Tolong diperhatikan ta!' (Rekaman 4)

(2) "Ayo digarap dhewe!"

*Ayo digarap dewe!]

'Ayo dikerjakan sendiri!' (Rekaman 7)

(3) "Ahmad disimak coba, bene presa tekan ngendhi ayo!"

[Ahmad disima? coba, bene presa təkan ngəndi ayo!+

'Ahmad disimak coba, biar tau sampai mana ayo!'(Rekaman 2)

(4) "Mpun sakniki mirengake mbokan, nek ora hiso ora munggah temenan. Oraan tak unggahke ben rasakna nek ora munggah!"

*Mpun sakniki mirəyake mboan, ne? ora hisa ora mungah təmənan. oraan ta? uygahake ben rasakna ne? ra mungah!+

'Sudah sekarang dengarkan hendaknya, kalau tidak bisa tidak naik beneran. Tidak saya naikkan biar rasakan kalau tidak naik!' (Rekaman 6)

Pada tuturan (1) Sebagai tuturan yang mengandung pragmatic permintaan tuturan "tulung digateake ta" Memiliki tingkat kesantunan yang tinggi karena dibubuhi penanda kesantunan "tulung" sehingga kadar tuturannya cenderung rendah. Pada tuturan (2) pembubuhan penanda kasantunan ayo guru menginginkan siswanya agar benar-benar mengerjakan sendiri. pembubuhan penanda kesantunan ayo juga berfungsi memperhalus kadar tuturan dalam imperatif bujukan. Pada tuturan (3) dengan membubuhkan kata coba, maka kadar tuturan dalam imperatif suruhan cenderung lebih lembut. Hal ini akan berbeda apabila penanda kesantunan dalam tuturan tesebut dihilangkan. Penghilangan penanda kesantunan tersebut menyebabkan tuturan itu memiliki kadar tuturan yang langsung, keras, dan kasar sehingga dapat ditafsirkan sebagi tuturan yang mengandung maksud imperatif suruhan yang kasar. Pada tuturan (4) memiliki kadar tuturan yang sangat tinggi, karena ditambahkannya penanda

Vol. 1 No. 1 / April 2018

$\mathrm{Al}$ - Mudarris homepage: http://e-journal.staima-alhikam.ac.id/index.php/al-mudarris/ 
kesantunan "mbokan" dapat menjadi lebih halus. Selain itu tuturan imperatif tersebut dapat memiliki makna yang baru, yaitu bermakna pemberian saran supaya siswa mendengarkan.

b. Kesantunan Pragmatik dalam Tuturan Deklaratif

1) Kesantunan Pragmatik dalam Tuturan Deklaratif

Dalam penelitian ini ditemukan tuturan deklaratif yang bermakna pragmatik suruhan, persilaan, larangan.

a) Tuturan Deklaratif yang Mengandung Makna Pragmatik Suruhan

(1) Kurang sero semono!"

*Kuray səro səmono!+

'Kurang keras segitu!' (Rekaman 2)

Pada tuturan di atas merupakan bentuk deklaratif yang mengandung maksud memberitahukan kepada siswa kurang keras saat membaca, maka dari bentuk deklaratif itu akan memunculkan maksud imperatif suruhan agar siswa lebih keras lagi.

b) Tuturan Deklaratif yang Mengandung Makna Prakmatik Persilaan

(1) Siswa: "Bu kula ajeng ting wc bu."

Siswa:* Bu kula ajəy tIn wc bu?+

Siswa: 'Bu saya mau ke toilet Bu.' Guru: “Ow yo.” Guru:[Ow yo] Guru: 'Ow ya.' (Rekaman 2)

Pada tuturan di atas mengandung makna persilaan dalam bentuk deklaratif guru mempersilahkan siswa yang mau ketoilet.

c) Tutran Deklaratif yang Mengandung Makna Pragmatik Larangan

(1) "Bilal kok dolanan mawon!"

[Bilal ko? dolanan mawon!]

'Bilal kok mainan saja!' (Rekaman 3)

Pada tuturan di atas merupakan bentuk deklaratif yang mengandung maksud memberitahukan kepada siswa untuk memperhatikan, maka dari bentuk deklaratif itu akan memunculkan maksud imperatif larangan agar siswa tidak ramai saat guru menerangkan.

2) Kesantunan Pragmatik dalam Tuturan Interogatif

Tuturan interogatif merupakan tuturan yang menggunakan kalimat pertanyaan (interogatif). Dalam penelitian ini ditemukan tuturan interogatif yang bermakna perintah dan larangan.

a) Tuturan Interogatif yang Mengandung Makna Pragmatik Perintah

(1) "Riyan kok malah ra disimak?

[Riyan ko? malah ra disima??]

'Riyan kok tidak disimak?' (Rekaman 6)

Pada tuturan di atas yang dituturkan oleh guru kepada siswa hanya memerlukan jawaban dari siswa yang bernama Riyan terhadap pertanyaan yang dikemukakan guru. Akan tetapi apabila tuturan itu dilihat secara pragmatik mengandung pragmatik imperatif perintah supaya siswa tersebut menyimak.

b) Tuturan Interogatif yang Mengandung Makan Pragmatik Larangan

(1) "Yoga malah ngalamun?"

*Yoga malah yalamUn?+

'Yoga kok melamun?' (Rekaman 7)

Pada tuturan di atas apabila dilihat secara pragmatic mengandung pragmatik imperatif larangan agar Yoga tidak melamun saat guru menerangkan. Munculnya

Vol. 1 No. 1 / April 2018

$\mathrm{Al}$ - Mudarris homepage: http://e-journal.staima-alhikam.ac.id/index.php/al-mudarris/ 
maksud imperatif larangan dilatarbelakangi oleh tindakan Yoga yang tidak memperhatikan saat guru membacakan soal.

\section{KESIMPULAN}

Berdasarkan hasil penelitian mengenai tuturan imperatif Bahasa Jawa yang dituturkan oleh Guru, dapat disimpulkan hal-hal sebagai berikut. (1) Wujud pragmatik imperatif diperoleh 10 wujud yaitu imperatif perintah, suruhan, permintaan, desakan, bujukan, imbauan, ajakan, anjuran, larangan, serta "ngelulu". (2) Faktor-faktor penanda kesantunan yang meliputi Kesantunan linguistik yang ditemukan yaitu meliputi panjang pendek tuturan, urutan tuturan, intonasi dan isyarat-isyarat kinestik tertentu, dan faktor ungkapan-ungkapan penanda kesantunan yang meliputi penanda kesantunan "tulung" "ayo", mbok/mbokan, dan "jajal".

Adapun kesantunan pragmatik imperatif yaitu bentuk deklaratif yang ditemukan dalam penelitian ini yaitu tuturan deklaratif yang menyatakan makna pragmatik imperatif suruhan, persilaan dan larangan, sedangkan bentuk interogatif yang ditemukan dalam penelitian ini yaitu interogatif bermakna pragmatik imperative perintah dan larangan.

\section{DAFTAR PUSTAKA}

Arikunto, Suharsimi. 2013. Prosedur Penelitian Suatu Pendekatan Praktik. Jakarta:Rineka Cipta.

Mulyana. 2005. Kajian Wacana: Teori, Metode Dan Aplikasi Prinsip-Prinsip Wacana. Yogyakarta:Tiara Wacana.

Sudaryanto. 1993. Metode Dan Aneka Teknik Analisis Bahasa Pengantar Penelitian Wahana Kebudayaan Secara Linguistis. Yogyakarta: Duta Wacana University Press. 